\title{
EDITORIAL
}

\section{SOCIEDADE CONTEMPORÂNEA E O PAPEL DA ODONTOLOGIA ESTÉTICA}

\author{
Juliana Felippi de Azevedo Bandeira*, Márcia Tosta Xavier**, Alena Peixoto Medrado***, \\ Urbino Tunes****
}

\begin{abstract}
* Graduação em Odontologia pela Universidade Federal da Bahia (2001), especialização (2003), mestrado (2005) e doutorado (2009) em Dentística Restauradora pela Faculdade de Odontologia de Bauru Universidade de São Paulo. Professora adjunta do curso de Odontologia da Escola Bahiana de Medicina e Saúde Pública; docente do curso de atualização em Estética Dental da Universidade Federal da Bahia e da Escola Bahiana de Medicina e Saúde Pública. Coeditora da Revista Bahiana de Odontologia.

** Graduação em Química pela Universidade Federal do Rio de Janeiro (1977), Mestrado em Bioquímica pela Universidade Federal do Rio de Janeiro (1983) e Doutorado em Bioquímica pela Universidade Federal do Rio de Janeiro (1991). Pós Doutorado em Bioquímica de Microrganismos na Fundacion Campomar, Buenos Aires, Argentina. Professora adjunta da Escola Bahiana de Medicina e Saúde Pública. Coeditoria da Revista Bahiana de Odontologia.

*** Graduação em Odontologia pela Universidade Federal da Bahia, mestrado e doutorado em Patologia Humana e pósdoutorado desenvolvido no Centro de Pesquisas Gonçalo Moniz, pela Fundação Oswaldo Cruz/ UFBA. Professora adjunto da Universidade Federal da Bahia e da Escola Bahiana de Medicina e Saúde Pública. Coeditora da Revista Bahiana de Odontologia.

**** Graduação em Odontologia pela Universidade Federal da Bahia (UFBA), Mestrado em Odontologia Clínica pela UFBA e Doutorado em Imunologia - PPglm / Instituto de Ciências da Saúde-UFBA. Especialista em Periodontia Social pela University of Illinois at Chicago (UIC/USA), Periodontia (ABO/BA/UFBA), em Metodologia do Ensino Superior (UFBA) e Estomatologia (CFO), Aperfeiçoamento em Ensino Odontológico pela University of Illinois at Chicago (UIC/USA), e Aperfeiçoamento em Gestão Universitária. Professor Titular da área de Periodontia do Curso de Odontologia da Escola Bahiana de Medicina e Saúde Pública (EBMSP); Coordenador do Curso de Graduação em Odontologia da EBMSP e Coordenador do Programa de Pós-graduação stricto-sensu (Mestrado) em Odontologia da EBMSP. Editor-chefe da Revista Bahiana de Odontologia.
\end{abstract}

A sociedade contemporânea apresenta grandes exigências estéticas; a aparência física desempenha um papel importante nas interações sociais humanas. Há uma busca incessante pela beleza e pela juventude, que não se restringe apenas aos modelos ou candidatos de concursos de beleza, mas também atinge as pessoas comuns. Beleza física comumente se torna objeto de desejo e se associa ao poder, ao sucesso e a aceitação social.

A saúde é um aspecto relevante quando se considera a conceituação de estética. A Organização Mundial de Saúde (OMS) ${ }^{(1)}$ define saúde como um estado de completo bem-estar físico, mental e social. Para a OMS, a saúde não está restrita à mera ausência de doença ou de enfermidade, mas a um estado positivo e multidimensional que envolve três principais domínios, que contemplam os aspectos físicos, psicológicos e sociais. Gozar do melhor estado de saúde que é possível atingir constitui um dos direitos fundamentais de todo o ser humano, sem distinção de raça, de credo religioso, de opção política, de condição econômica ou social.(1)

Neste contexto, a aparência do sorriso é uma característica importante na determinação de um rosto esteticamente agradável e, portanto, desempenha um papel fundamental nas relações interpessoais. Isso significa que pessoas com problemas odontológicos visíveis podem ter dificuldade nas 
suas relações pessoais e profissionais, o que interfere diretamente na sua autoestima. ${ }^{(2,3)}$

Entre os fatores importantes que afetam a aparência dental destacam-se; a cor dos dentes, sua forma, tamanho e posição; qualidade da restauração; posição do lábio superior, visibilidade dos dentes, quantidade de exposição gengival e o alinhamento geral, especialmente dos dentes anteriores. (4) E embora cada fator possa ser considerado isoladamente, todos os componentes devem agir em conjunto para criar uma entidade harmônica e simétrica que produz o efeito final favorável à estética facial. ${ }^{(4)}$

Com os importantes avanços na área da Odontologia cosmética, através do surgimento de novos produtos, técnicas e tecnologias, tornou-se possível corrigir as imperfeições estéticas e aumentar a qualidade de vida dos pacientes. ${ }^{(3)}$ Os procedimentos são indicados para melhorar a aparência do sorriso, mas também para auxiliar na função mastigatória e prolongar a resistência da estrutura existente, além de preencher lacunas que o desalinhamento dos dentes provocam, resultando em uma melhora sensível da saúde bucal.(3)
Desta forma, a Odontologia estética está ganhando cada vez mais importância na vida das pessoas e vem deixando de ser um privilégio dos ricos e famosos, uma vez que a sociedade vivencia o fenômeno da democratização da informação e do crescente consumo de produtos e serviços.

\section{REFERÊNCIAS}

1. Constituição da Organização Mundial da Saúde (OMS/WHO) - New York, 1946.

2. Montero J, Gomez-Polo C, Santos JA, Lorenzo MC, Albaladejo A. Contributions Of Dental Colour To The Physical Attractiveness Stereotype. J. oral rehabil. 2014; 41:768-782.

3. Manipal S, Mohan CSA, Kumar DL, Cholan PK, Ahmed A, Adusumilli P. The importance of dental aesthetics among dental students assessment of knowledge. J. Int. Soc. Prev. Community Dent. 2014;4(1):48-51.

4. Tin-Oo MM, Saddki N, Hassan N. Factors influencing patient satisfaction with dental appearance and treatments they desire to improve aesthetics. BMC Oral Health. 2011;11:6. 